\title{
MEMORIA DE LAS RAÍCES EN LA POÉTICA DE ALONSO ARES
}

\author{
José M aría BALCELLS
}

Universidad de León

La lectura de los tres conjuntos líricos del poeta leonés Adolfo Alonso Ares (Astorga, 1956) aparecidos en los años finales del XX, nos revela una personalidad literaria muy singular, en virtud especialmente de la gran coherencia de su universo creativo, una coherencia que se manifiesta tanto desde la vertiente temática como formal. Los tres libros a los que se alude ( $E l$ vértigo sagrado, 1998; Un renglón infinito, 1998; y Alacenas blancas, 1999)1 poetizan, en efecto, un único motivo inspirador, y lo plasman desde un único lenguaje expresivo. El pretexto, y a la vez fuente, del canto, es el sentimiento de pérdida del paraíso de la infancia, y el habla poética en la que se vierte tal sentimiento es un neosurreal ismo sui generis. La coherencia de Alonso A res a la que nos hemos referido resulta radical, porque su mundo poético consiste, en suma, en ofrecernos distintas formas de un mismo tema y de un mismo decir.

La inspiración en el paraíso perdido de la infancia es un factor creacional nada infrecuente en la poesía española contemporánea, pero sí es insólito abundar con tanta reiteración en el orbe de la niñez, y de modo tan ostensible y casi exclusivo. Ahora bien: unidos al tema esencial antedicho podemos advertir otros pretextos líricos relevantes, así el del tiempo, el del ámbito familiar, y el del espacio geográfico y climático, pretextos todos que se formulan desde la nostal gia de un ayer ido irremisiblemente, pero al que el yo lírico se aferra una y otra vez, evocándolo sin cesar. Quizá la causa básica de esta poética resida en el convencimiento del hablante de que su creación se origina en el regreso continuado y fiel a su lar nativo, un retorno que alimenta y en el que se funda su verso, su idiosincrasia literaria y por ende la salvación personal de su identidad y de sus creaciones artísticas.

\section{Del espacio y del tiempo}

La memoria de la infancia supone, así pues, el cimiento de la literatura de Adolfo Alonso Ares, pero ya adelantábamos que en esa rememoración se involucran otros pretextos, desde el espacial hasta el metafísico. El espacial es un motivo diverso, porque tiene que ver con la naturaleza comarcana originaria, con el campo y sus trigos, con la gélida climatología del invierno, con el pueblo de nacimiento y con la casa que fue su morada primera. Estos espacios, estos

\footnotetext{
${ }^{1}$ He aquí las respectivas referencias bibliográficas: El vértigo sagrado. Madrid (Endymion) 1998, 87pp.; Un renglón infinito. León (Diputación) 1998, 86pp.; Alacenas blancas. Valladolid (Junta de Castilla y León) 1999, 107pp.
} 
ámbitos son recurrentes en los libros objeto de estas notas, pero progresivamente van incrementando su presencia de libro en libro, hasta el punto de asumir un incuestionable protagonismo en la poética del autor.

La primacía de lo espacial parece aludida implícitamente en el título Alacenas blancas, con vocablos que remiten a la esfera doméstica (alacenas), al paisaje nevado, y asimismo al paso del tiempo. Pero el devenir temporal es el motivo metafísico más importante en los versos de Alonso Ares, en cuya poesía el transcurso de los años no se refleja con sereno estoicismo, sino con honda tristeza, e incluso con temor, pero siempre con estremecimiento.

El yo poemático se duele del tiempo ido, porque emparejó la consumación de la infancia y el alejarse de los contornos en los que se había desenvuelto su niñez. El tiempo ha convertido en imágenes y sensaciones pretéritas aquel paraíso de otros días. Pero el tiempo seguirá segando edades y abatirá también el presente, cuya felicidad se ha creado a imagen y semejanza del pasado feliz que perdura como savia nutricia del hoy y del mañana. Nada halagüeño puede provenir, por tanto, del inflexible avance del tiempo, que dejó atrás el pasado, sepultará también el presente, y acabará incluso con el futuro, aunque no con las palabras que habrán dado y dejado testimonio poético de la fortísima simbiosis entre una voz lírica y su perimundo ancestral.

Uno de los aspectos enjundiosos de la poética del tiempo de Alonso Ares reside en la recreación de tópicos de la historia literaria, y el conjunto Un renglón infinito es ilustrativo al respecto, y desde el título mismo, ya que alude al lugar común del libro de la vida (renglón), y a la problemática de la temporalidad superada (infinito). Entre los tradita de esta obra, llamaré la atención acerca de tres de gran resonancia en la poesía española secular, y singularmente en la del Barroco, y que tuvieron una brillante reelaboración en el numen de Quevedo. Son los tópicos de la muerte personificada que acude a buscar al hombre ("Detesto la indolencia"); el de la muerte de la propia muerte, porque ni siquiera la muerte escapa a su ley inflexible, así en los versos finales de "Podré sentir ahora vuestros dados": "Otras veces el tiempo que contiene/ aquel reloj de arena/ que muere sobre el muelle de la casa", y el de la muerte de las edades sucesivas del ser humano, comenzando por la muerte de la niñez, en el poema XXXIV y último del libro:

Los inviernos nacieron como universos viejos
detrás del libro roto que deshojaba un niño
y el niño frente al aire en una casa muerta
expiró como escarcha que abandonan los siglos.

\section{Un neosurrealismo genuino}

La manera de estructurar Alonso Ares sus conjuntos poéticos es idéntica, pues los configura a modo de poema unitario, de poema-libro, siempre conformado en varias secciones interiores, pero con numeración continuada en 
guarismos romanos. De este modo, cada obra comprende un todo orgánico, subdividido en fragmentos que se suceden, aunque se distribuyen en varios apartados, presididos éstos por versos que preludian y sintetizan la esencia del contenido de los textos que van a continuación. El poeta no parece tener preferencia por un tipo constante y sistemático de agrupaciones versales, ya que utiliza en sus obras contornos diversificados. Sin embargo, computar las sílabas de sus líneas poéticas nos depara una métrica tradicional, clásica, en la que tienen gran peso cómputos del abolengo del heptasílabo, el endecasílabo y el alejandrino, entre otros ritmos.

La presentación opaca del discurso es característica en la poética del autor, que trata de conseguir la opacidad en virtud de un persistente lenguaje de cuño surreal apoyado en atrevidas imágenes, pero merced también a una sintaxis a veces descoyuntada, y a través igualmente de una puntuación que se apoya en el punto y prescinde generalmente de comas y de otros signos. Un hermetismo radical de marchamo surrealista empareja, así pues, los libros del autor, en los que pocas veces afloran textos en los que se pone énfasis en una inteligibilidad inmediata. Como ejemplo de ese último supuesto consignamos aquí los fragmentos XXIII y XXIV de Alacenas blancas, tan alejados de la extrañeza metafórica habitual en el idiolecto del escritor astorgano.

Un apunte final sobre el neosurrealismo de Alonso Ares: entendemos que, más que responder a la opción por una tendencia poética, la palabra surreal parece brotar de su férvida personalidad e imaginación personales, porque el poeta se expresa también en lenguaje muy abstracto en sus creaciones plásticas, que están en sintonía artística con las poéticas. La expresión surrealista, en consecuencia, emerge con un al to grado de naturalidad genuina de la pluma del autor, lo que no obsta para que se construya con artificio en no pocas ocasiones. Al respecto, un recurso muy llamativo y muy original a la par es el constructivismo de rimas internas que se aprecia en textos como "Yo soy acaso eso que pensábais", con que se inicia Un renglón infinito, o "No soy ojo nublado de blancas mariposas", del mismo libro.

\section{EI liquen de los robles}

Quien conozca los perfiles temáticos y formales que singularizan la poética de Adolfo Alonso A res no encontrará diferencias básicas de uno u otro carácter en su poemario El liquen de los robles ${ }^{2}$. A hí está su mundo lírico inequívoco, sus motivos dominantes, sus rasgos técnicos más comunes. Empero, cada libro del autor es distinto, cada libro es una nota de un canto que nace del mismo hontanar. Siendo así, la tarea crítica habrá de consistir en poner de relieve, en cada una de las sucesivas entregas poéticas del escritor astorgano, los rasgos propios

\footnotetext{
${ }^{2}$ Adolfo Alonso Ares, El liquen de los robles, Santiago de Compostela (Follas Novas) 2000,
} $53 \mathrm{pp}$. 
que hacen divergente una obra de otra, en el marco de los extraordinarios parecidos que las asemejan.

Ya el título El liquen de los robles nos conduce al escenario de la niñez, en un contexto geográfico de frío y de heladas, donde se levanta una casa que fue el ámbito de la infancia. Casa entrañable en la que la cocina era centro familiar y el huerto una apertura a la belleza y al perimundo paisajístico. Rodeadas de enseres cotidianos, las brasas hogareñas crepitaban cálidamente en aquel entorno doméstico en el que brotó la raíz lírica del hablante poemático.

A modo de reconocimiento al espacio de la casa como manantial del poeta, los textos primero y último de este conjunto se centran en ella, encuadrando el contenido de la obra, un encuadre que refuerzan incluso las estructuras lingüísticas de los versos con que principia ("Tengo frente a la casa del silencio") y termina ("Y la casa/ que tengo frente al patio de las lilas"). A quella casa simbolizó el paraíso infantil, un paraíso rodeado de bella naturaleza, pero desde la que asi mismo se veía que no todo era paradisíaco alrededor. Puertas afuera, aparece la miseria, la necesidad, el hambre, mucha hambre. He aquí la lección para el niño que es y será poeta. Aquella casa estuvo en el sitio preciso para contemplar cómo florecía lo bello, pero también para que tampoco quedaran ocultas las realidades más tristes y penosas de las circunstancias humanas.

Casa de ayer evocada líricamente desde hoy. Días pretéritos revividos desde el presente. A tmósfera del pasado distante en espacio y tiempo, pero anidada en el espíritu. La voz lírica recuerda, y al recordar constata el transcurso temporal, llave maestra en la poética de Alonso Ares. Anótense los campos semánticos de los poemarios del escritor leonés, y se apreciará que la dialéctica del discurrir cronológico y sus secuelas siempre emerge como uno de los referentes neurálgicos en todos y cada uno de los conjuntos, y por ende también ocurre en El liquen de los robles.

El recuerdo de las vivencias que quedaron en la lejanía de los años hace nacer una entristecida nostalgia, pero la comprobación del deterioro de las cosas propicia una patética y desazonadora impotencia. El tiempo no se detiene, y arruina, arrumba, pudre, mata. Seguimos moviéndonos en el universo de Alonso Ares: paraíso de la infancia, días que fueron pero no se olvidaron, decrepitud de cuanto resplandecía, y la comprobación del imponderable de la muerte.

Y ahora volvamos a los campos semánticos que habíamos establecido, y fijémonos bien: en El liquen de los robles al canza la muerte un relieve especialísimo, muy por encima del que alcanza su responsable esencial, el tiempo transcurrido. Porque en este libro asoma más la muerte que cual quier otra instancia, e incluso hay estrofas que nos sobrecogen por su insistencia al respecto. Léase la que da comienzo al poema décimo:

Suena a nadie, verdad que mira y muere.

Tengo presente al tiempo en la ceniza

pájaros fríos, lentos cangilones

de una noria que muere y se desliza 
Nótese que ningún verso carece de la referencia mortal, aunque el tercero la explicite a través del adjetivo "fríos". Ninguna otra estrofa del libro acumula tan terrible concentración fúnebre, pero en El liquen de los robles rebosan las líneas que plasman cenizas, despojos y aconteceres sepultados en el tiempo. $Y$ quizá tenga lógica tanta recurrencia en la muerte, tanto énfasis en lo perecido. La mitificación de la infancia es la causa. El paraíso infantil está tan mitificado, tanto, que su pérdida es padecida como muerte voraz y omnipresente que no deja de visualizarse en todo y por todo.

Pero pasemos ya a considerar algunos aspectos del lenguaje poético de $E l$ liquen de los robles. La obra se ha elaborado dentro de los parámetros típicos del autor: lengua de cuño surreal, estructuración de poema-libro en el que cada texto funciona a modo de fragmento del conjunto, y verso de marchamo clásico, con una preferencia marcada por endecasílabos y versos heptasilábicos, aunque se usan versos más cortos en ocasiones.

Cabe subrayar en este conjunto que el autor se vale de la estrofa esporádicamente, así del cuarteto en la composición XVI, y de una suerte de serventesios en los poemas X y XI, estrofas en las que quedan libres de rima los versos 1 y 3 de cada agrupación. Procede añadir, además, que no carece de vertiente lúdica El liquen de los robles, como lo demuestra el poema XXXIII, en el que un donoso juego con las rimas contrapuntea la graveza de la obra y rebaja un tanto la espesa sombra que deja tras de sí el corrosivo caminar del tiempo sobre las desvencijadas huellas de antaño.

\section{Del rojo al negro}

En el prólogo que escribió José Hierro al libro Del rojo al negro, ${ }^{3}$ en el que convergen la creación poética de A dolfo Alonso A res y la pictórica de Luis Feito, afirma el poeta cántabro que no es abordable la poesía por medio de la razón, y que ni siquiera su propio autor es capaz de explicar la literalidad de sus versos. En cambio, añade, lo que la razón no entiende, sí lo capta la sensibilidad. Y así es, ciertamente. Sin embargo, estas afirmaciones son compatibles con que aceptemos que un lector asiduo de la obra de un poeta puede reconocer en él determinadas claves, no de desciframiento fidedigno, pero sí de aproximación a su universo más propio.

A pelando a la garantía de habernos demorado en la lectura de los libros anteriores de A lonso Ares, estamos en condiciones de asegurar que, pese a las apariencias de superficie, tampoco aquí el poeta astorgano se ha desviado, ni de sus técnicas literarias más características, ni del imaginario que lo singulariza. No caigamos, por tanto, en el error de creer que el pretexto de Del rojo al negro son las variaciones oníricas que suscitan ambos colores a la persona que nos habla desde cada poema. Tales variaciones, que obviamente las hay, son un pretexto, una nueva excusa, para reincidir en su poso más hondo, en su poso de siempre,

\footnotetext{
${ }^{3}$ Adolfo Alonso Ares. Luis Feito, Del rojo al negro, Madrid (Sial ediciones) 2000, 43pp.
} 
en el poso de una infancia que sólo se perdió en los calendarios, no en los hontanares de su espíritu.

Y esa infancia, claro, fue vivida en una tierra concreta, ante los horizontes que se abren desde Astorga. Los lectores de A lonso A res lo saben bien, pero, aun sabiendo que lo saben, el locutor poemático ni posterga esas claves, ni las da por sentadas, sino que se reafirma en ellas proclamándolas inequívocamente desde la estrofa inicial del primero de los textos de Del rojo al negro:

\section{Pero retorno al mundo de la sombra al hemisferio azul que me conoce y está junto al misterio de los astros.}

A hora bien: una vez regresado fictivamente a ese hemisferio del que nunca se exilió, y como siempre acaece en la poética de este autor, observamos que también en este libro se plasman inflexiones diferenciales dentro de las líneas maestras de su obra lírica. Aquí el decantado específico consiste en el desarrollo del manifiesto propósito que se enuncia en los tres versos con que comienza el fragmento tercero, en el cual culmina el prólogo poético puesto al frente del libro:

Quiero ahondar en lo oscuro

latir como los pechos que conocen

un pétalo que sangra

La finalidad que asume el hablante no puede enunciarse con más nitidez: el ahondamiento en la entraña de la negrura para conocerla muchísimo más, para esclarecerla. Y la guía del camino será la roja luz de dolor encendido que dimana del corazón. Las posibilidades connotadoras de misterio resultan palmarias, pero aquí no se persiguen metas gnoseológicas trascendentales, sino nuevas vías de acceso al reto permanente del re-conocimiento del ámbito interior a través del prisma del entorno nativo.

Y no se logra ese reconocimiento de uno mismo si no es merced a una comprensión bien profunda de la fuente originaria. En su virtud, hay que acudir constantemente a ella desde lo más hondo. Dado que esas raíces (negro) son aquí examinadas desde su ladera oscura, el título del libro explicita ese viaje cordial (rojo) hacia los ámbitos primeros de la persona.

Las raíces son examinadas, en este conjunto poético, a partir de un negro prisma, pero es negro por motivos muy justificables, entre ellos por el de que el pasado anida en la sombra, pues el paso del tiempo, y la muerte, dejaron su luctuosa huella sobre aquellos días; porque la tierra propia, a la que no se nombra, es lugar invernal; e igual mente porque la representación del pretérito se efectúa desde el camino hodierno a oscuras, y de retorno, al ayer primero.

La única luz posible, durante ese itinerario, nace del corazón, de la sangre. Pero ocurre que esa luz encendida tuvo comienzo también en el innombrado lu- 
gar de procedencia. A hí brotaron los latidos de la sensibilidad, el apasionamiento, la atención fija en la belleza, el dolor solidario y la conciencia del tiempo y de la muerte.

Ir del rojo al negro, sí, pero en una continuada travesía de reflujo vivificante. Rojo en pos del negro a través de la oscuridad, y rojo que se intensifica al reacudir a la infancia en la que se funda, pero habiendo de atravesar, día a día, noche a noche, la cada vez más densa y tupida capa del tiempo.

A notaba José Hierro en el prólogo de referencia que el endecasílabo es el ritmo mayoritario de este libro, y es verdad, tal como ocurre en las otras entre gas poéticas del lírico astorgano, que también se vale habitualmente del verso blanco en los textos de que consta cada nuevo libro. Tampoco falta en ellos el re curso esporádico a las rimas, aquí (en uno de los fragmentos, el VI) materializando un peculiar hibridismo de serventesio y redondilla. Esta práctica contrasta con la que se sigue en los demás momentos de Del rojo al negro, erigiéndose en una suerte de sello con que se rubrica, en cada supuesto, la especificidad versal deAlonso Ares.

Dice José Hierro, además, que las imágenes de esta obra son sonámbulas. Y resulta más que cierto, no habiendo tampoco en este punto novedad al guna respecto a las pautas que distinguen al poeta. Con todo, acaso sí haya en Del rojo al negro una cota más alta de onirismo, propiciada por ese abandonarse a la absorción de los colores.

\section{Plegaria de metal}

En 2003 obtuvo Adolfo Alonso Ares el galardón del XIII premio Jaime Gil de Biedma de poesía que otorga la Diputación de Segovia. Este nuevo reconocimiento al poeta recayó en su libro Estucos del pasado, libro que, al publicarse, cambiaría su título por el de Plegaria de metal (memoria de la tarde)4. Esta segunda titulación era una de las varias que sopesó el autor antes de decidirse por ella, convirtiéndola en definitiva. Ciertamente, el nuevo título reviste más plasticidad que el anterior, y su relación con el contenido de la obra resulta menos explícito que el precedente, pero no menos estrecho, sino acaso más. Y diré por qué.

Estucos del pasado hace clara referencia a las claves temáticas primordiales del lírico astorgano, claves que convergen en la rememoración de lo acaecido en el pretérito, rescatándolo en cuanto lo consiente la palabra poética. A primera vista, Plegaria de metal (memoria de la tarde) difiere del título sustituido, pero en realidad difiere en apariencia. Repárese en el concepto "memoria", que se justifica apelando al tiempo ido. Repárese también en la palabra "tarde", que apunta al declinar del día, implicando una buena porción del mismo ya consumida, y por tanto pasada, aunque ese pasado recién acabe de suceder. Y ambas palabras, constituyendo la expresión "memoria de la tarde", van entre paréntesis, como intentando arrojar alguna luz acerca del título Plegaria de metal, un título paradó-

\footnotetext{
${ }^{4}$ Adolfo Alonso Ares, Plegaria de metal (memoria de la tarde), Madrid (Visor) 2003, 82pp.
} 
jico si se toma en su sentido más ordinario, pero más patente si "metal" se descifra en la acepción figurada de "timbre de voz".

En cualquier supuesto, si cruzamos "plegaria" y "memoria" estamos en condiciones de aproximarnos al meollo profundo de esta entrega poética de Ares, epicentro que no es otro que el de una poetización reverencial del ayer, una poetización asociable al ámbito religioso, pero que en realidad se sitúa en un plano bien distinto. En corolario, podemos aseverar que en el trueque de un título por otro se ahonda más en la entraña de la obra, por mucho que una lectura inadvertida y apresurada de la misma pueda dar la sensación contraria. Sea como fuere, uno de los poemas del libro, el XLVIII, del que se extrajo su titulación, ilustra meridianamente el prisma a través del cual el autor enfoca cuanto venimos afirmando:

La memoria es legado de inocencias tiempo que ya pasó, salón de adobe plegaria de metal, viejo instrumento para encender hogueras alejadas

$Y$ hechas estas consideraciones, subrayemos que a cada libro que escribe, A lonso Ares coloca ante sí un reto día a día más y más difícil, el de lograr, como las aguas del Duero del romance de Gerardo Diego, que una obra tras otra entonen semejante canción, pero con distinta agua. Pero maticemos, porque nunca se trata exactamente de la misma canción, y nunca estamos ante la misma agua, aunque sí estamos siempre ante variaciones temáticas, imaginísticas, léxicas y rítmicas acerca de un universo inapelablemente suyo e identificador que distingue a este poeta de cualquier otro, distinguiendo asimismo su voz inconfundible de cualesquiera otras.

En ocasiones parece como si el reto al que acabamos de al udir fuese sentido por el poeta como un gravamen tan connatural en él como oneroso. Y la tentación de desviarse de su temática más genuina le asalta. En Plegaria de metal cabe advertir un amago de transitar sendas no holladas. El poeta se inclina por momentos hacia el vértigo de cantar lo nunca cantado antes, de introducir un cambio, un sesgo nuevo. Pero al cabo parece darse cuenta de que le tentaba un espejismo. Su imaginario personal lo llama otra vez a la fidelidad a las raíces, y éstas acaban venciendo. Su mundo es su mundo y no otro, y distanciarse de él, aunque sea por un lapso breve, constituye una veleidad que no conduce a otro camino que a reafirmarse en su sendero más originario.

Se podrían invocar, como muestra de cuanto sostenemos, distintos textos del centro del libro, como por ejemplo varios consecutivos a partir del XXVII. Desde allí, si no desde un poco antes, se diría que el poeta efectúa una simulación contrapuntística respecto a los asuntos en los que se sumerje de continuo. Pero el poema XLI termina con una estrofa que resulta iluminadora del tirón que 
reconducirá de nuevo al astorgano hacia y en pos de su savia más añeja, no sin acaso

\author{
Alli, nuestro misterio calcifica \\ las horas de lo incierto. \\ Su pesar se apodera de la lluvia \\ y siempre regresamos.
}

Es en ese ámbito en intrínseca coherencia con su escritura precedente donde el poeta leonés encuentra sus acentos más auténticos, y por este motivo en Plegaria de metal asistimos a rutas ya transitadas, pero que se nombran, que se dicen renovadamente con un decir que suena a prístino, a inaugurado. La capacidad de crear y crear variaciones sobre un idéntico fermento inspirador resulta inaudita, portentosa, increíble, y se diría que no tienen fin las posibilidades del autor en esta línea, lo que le convierte en un verdadero virtuoso del lenguaje y en concreto de la escritura de índole surreal que caracteriza, un libro sí y otro también, su habla poética. Ese tipo de expresión que le nace de modo tan congé nito, y esos motivos poéticos a los que no podría desoír, aunque quisiera, cohe sionan y traban de tal modo su obra que hacen de Alonso Ares uno de los líricos más coherentes del cruce literario finisecular.

Tocante a técnicas formales, en Plegaria de metal no advertimos intento de buscar alternativa alguna a la poética a la que Adolfo Ares ha ido acudiendo en cada uno de sus libros. En esta entrega de 2003 la técnica, parecidamente a la temática, se mira en el espejo de sí misma, y se consolida reafirmándose, pero a la vez perfeccionándose, logrando, merced a un pulso más y más seguro y cuajado, momentos de redonda y consumada rotundidad, así en el poema XXVI

En la muerte que late sobre un cetro

y ordena la esperanza

deposité el sudor que en este tiempo

había recogido.

Luego corté la ausencia,

dejé su poso áspero en el suelo

del salón de un palacio

y me marché desnudo. 